\title{
Two Distinct Humanized Monoclonal Antibodies for Immunotherapy of Ovarian Cancer
}

\author{
Gregory Lee ${ }^{1,2}$, Cheng-yuan Huang ${ }^{1}$ and Bixia Ge ${ }^{1,2}$
}

${ }^{1}$ UBC Center for Reproductive Health, Vancouver, Canada

${ }^{2}$ Department of Pathology, Shantou University Medical College, Shantou, China

\begin{abstract}
Two monoclonal antibodies (Mab) were selected for development of anti-cancer drugs targeting ovarian cancer. RP215 Mab was shown to react with a carbohydrate-associated epitope detected mainly in the heavy chains of cancer cell-expressed immunoglobulins which are essential for the growth/proliferation of almost all human cancer cells. GHR106 Mab, on the other hand, reacts specifically with $\mathrm{GnRH}$ receptor on the surface of almost all cancer cells. In this review, efforts were made to use an ovarian cancer cell line, OC-3-VGH as the experimental model to study these two Mabs in murine and humanized isoforms including humanization, comparative biochemical and immunological characterizations. Surface binding of either of these two Mabs can result in apoptosis and complement-dependent cellular cytotoxicity to this ovarian cancer cell line and others. Both murine Mabs were humanized and shown to be bioequivalent with respect to affinity and biospecificity to their murine counterparts through extensive biochemical/immunological studies. Therefore, preclinical and clinical studies were warranted to continue the investigations of these two potential anti-cancer drug candidates for therapeutic treatments of ovarian cancer.
\end{abstract}

Keywords: Humanized monoclonal antibodies RP215; CA215; GnRH receptor; GHR106

\begin{abstract}
Abbreviation: CDC: Complement-Dependent Cytotoxicity; CDR: Complementarity Determining Region of Immunoglobulin; Fab: Fragment, Antigen-binding Region of Immunoglobulin; Fc: Fragment, Crystallizable Region of Immunoglobulin; FR: Framework Region of Immunoglobulin; GnRH: Gonadotropin-releasing Hormone; hGHR106: Humanized GHR106 Mab; hRP215: Humanized RP215 Mab; IgG: Immunoglobulin G; Mab: Monoclonal Antibody; mGHR106: Murine GHR106 Mab; mRP215: Murine RP215 Mab; siRNA: Small Interfering Ribonucleic Acid; TUNEL: Terminal Deoxynucleotidyl Transferase dUTP Nick End Labeling
\end{abstract}

\section{Background Information}

In 1987, a monoclonal antibody (Mab) designated as RP215 was generated against OC-3-VGH ovarian cancer cell line [1]. This ovarian cancer cell line is of serus origin established in 1986. It has been employed as a model to conduct most of the anti-cancer drug development studies in this review [1]. RP215 was later shown to react with a carbohydrate-associated epitope, detected mainly in cancer cellexpressed heavy chain of immunoglobulins and other immunoglobulin superfamily proteins designated in general as CA215 [2-4]. As demonstrated by several previous studies, cancerous immunoglobulins are essential for growth/proliferation of cancer cells, which was judged from several hypothesized mechanisms of actions as well as siRNA inhibition studies [5-7]. GHR106 Mab, on the other hand was found to react specifically with GnRH (Gonadotropin releasing hormone) receptor, which was widely expressed on the surface of almost all cancer cells [8-16]. This Mab was found to have biological actions similar to those of decade peptide analogs of GnRH $[9,17]$, including their respective patterns in gene regulations, and induced apoptosis to ovarian and many other cancer cells $[9,17]$. However, this Mab has a much longer half-life than those of the peptide analogs (days vs. hours).

Since ovarian cancer has the highest mortality rate among the known gynecological cancer in women [18], substantial efforts have been made in the past to search for antibody drugs which are effective in the immunotherapy of ovarian cancers [19]. By immunohistochemical studies, ovarian cancer cells in tissue sections revealed one of the highest positive staining with these two selected Mabs [20]. Therefore, OC-3VGH ovarian cancer cell line was used as the main model throughout the drug studies. The preliminary preclinical studies have been performed to evaluate these two potential anti-cancer drug candidates and to judge if they are suitable for applications in immunotherapy of ovarian cancer. Biochemical and immunological characterizations of the humanized forms of these two Mabs were performed to demonstrate the bioequivalence between these two isoforms and their corresponding murine Mabs. This might be one of the essential steps to validate humanized Mabs for future clinical trials in humans.

\section{Humanized Antibodies to CA215, hRP215}

To develop RP215-based anti-cancer drugs for human applications, it is essential to modify the original murine RP215 Mab into humanized forms $[17,20]$. The humanized versions of RP215 reported in this study, must be demonstrated to have affinity and specificity to CA215 comparable to or equivalent to, those of the original murine RP215, in particular, the antibodies or fragments with variable regions (Figure 1). For complete antibodies, the constant region of the heavy chain of IgG, and that of $\kappa$-light chain were constructed [20]. The humanized antibodies may be assembled in variety of forms including whole antibodies, fragments such as Fab, Fab', and $\mathrm{F}\left(\mathrm{ab} \mathrm{b}^{\prime}\right) 2$, as well as recombinantly produced single chain antibodies which are

*Corresponding author: Gregory Lee, Ph.D, 9117 Shaughnessy Street, Vancouver, V6P 6R9, Canada, Tel: 778-322-4651; E-mail: cgregorylee@gmail.com

Received February 20, 2014; Accepted March 27, 2014; Published March 31, 2014

Citation: Lee G, Huang C, Ge B (2014) Two Distinct Humanized Monoclonal Antibodies for Immunotherapy of Ovarian Cancer. J Cancer Sci Ther 6: 110-116. doi:10.4172/1948-5956.1000258

Copyright: ( 2014 Lee G, et al. This is an open-access article distributed under the terms of the Creative Commons Attribution License, which permits unrestricted use, distribution, and reproduction in any medium, provided the original author and source are credited. 
immunoactive to CA215. The resulting humanized forms and the murine RP215 usually contain substantially similar or identical CDR regions. CDR regions of the variable regions of both IgG chains can be determined by a numbers of known methods including that of $\mathrm{Wu}$ and Kabat and Clothia et al. [21,22].

Sandwich and/or binding immunoassays were used to demonstrate the substantial equivalence between humanized forms and murine RP215 [20]. Their respective affinity and specificity to the cognate antigen, the cancer cell-expressed CA215, are two important parameters to establish their substantial equivalence. The comparative binding curves of murine RP215 (or chimeric RP215) and other humanized isoforms are presented in Figure 2. These binding immunoassays were performed by using affinity-purified CA215 coated on microwells in order to determine the relative binding degree of coated CA215 to these humanized RP215 Mabs and to compare with that to the original murine RP215. CA215 was affinity-purified by RP215-linked affinity column from the shed culture medium from cultured OC-3VGH ovarian cancer cells. As shown, all of the humanized isoforms including FY1 to FY6 have comparable affinities with RP215. Estimates of affinity constants are given in Table 1A. The one with the highest affinity (FY4) was shown to have a dissociation constant (Kd) of $4.4 \mathrm{nM}$ to CA215. It was found to be comparable to that of the original murine RP215 Mab (4.2nM).

Previously, RP215 was established to have no cross-reactivity to normal human IgG. It reacts only with cancer cell-expressed CA215 that contains RP215-specific carbohydrate-associated epitope [2326]. Therefore, the humanized RP2 15 Mab should also have no crossreactivity to normal human IgG as expected through the results of binding assay [20]. The complete amino acid sequences of both heavy and light chains of the finally selected humanized RP215 Mabs are presented in Figure 1 for comparisons. Comparisons in sequence homology of different FR and CDR regions between murine and selected humanized isoforms are also presented in Table 2.

\section{Humanized Forms of Monoclonal Antibodies to Human GnRH Receptor, hGHR106}

GHR106 Mab is of murine origin and was converted to humanized forms designated as hGHR106 through the established procedures as described for hRP215 [20]. GHR106 recognizes specifically the
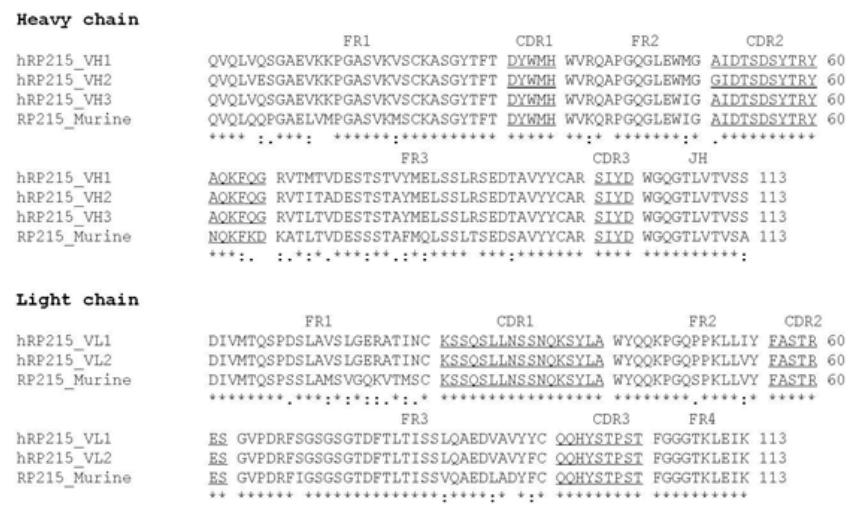

Figure 1: Comparisons of amino acid sequence of mRP215 Mab and three different hRP215 Mabs in the Fab regions of RP215 Mabs. The FR/CDR domains are defined along with the deduced sequence for comparisons.

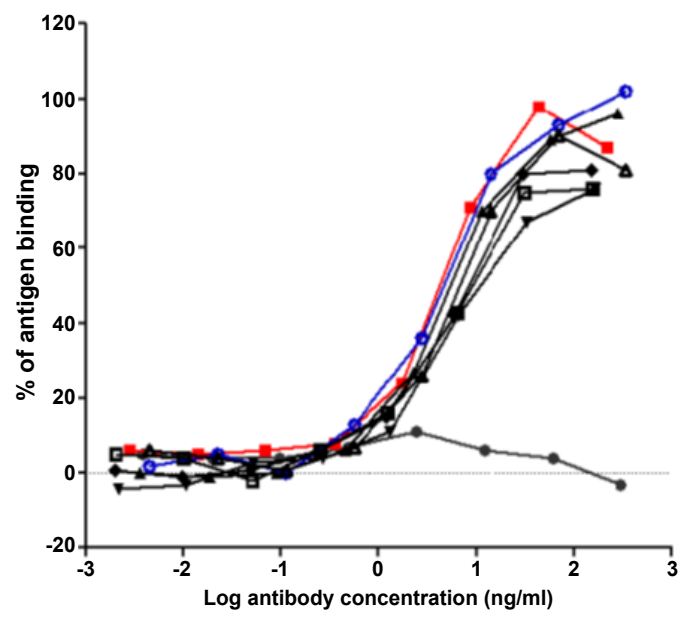

Figure 2: Binding immunoassays using affinity-purified CA215 coated microwells to determine the binding affinities of these humanized RP215 to CA215 and to compare with that of the original murine RP215.All of FY1-FY6 humanized isoforms have comparable affinities to RP215. Figure legends: : Neg. control, $\square$ : RP215 chimera, $\mathbf{A}$ :FY1, $\mathbf{\nabla}:$ FY2, : FY3, O : FY4, 口: FY5, $\triangle:$ FY6.

\begin{tabular}{|l|l|}
\hline Name of Antibody & Apparent Titer (nM) \\
\hline Negative control & NA \\
\hline RP215 chimera (with human IgG) & 4.2 \\
\hline FY1 & 5.7 \\
\hline FY2 & 13.1 \\
\hline FY3 & 8.4 \\
\hline FY4 & 4.4 \\
\hline FY5 & 9.6 \\
\hline FY6 & 7.1 \\
\hline
\end{tabular}

Table 1A: The estimates of dissociation constants of humanized RP215 and other different forms.

\begin{tabular}{|l|l|}
\hline Name of Antibody & Apparent Titer (nM) \\
\hline Negative control & 326 \\
\hline H64L42 & 13 \\
\hline H65L42 & 50 \\
\hline H66L42 & 43 \\
\hline H40L42 & 7 \\
\hline
\end{tabular}

Table 1B: The estimates of dissociation constants of humanized GHR106 and other different forms.

extracellular domains of human GnRH receptor, which is highly expressed on the surface of cancer cells of many human tissue origins [8-16]. hGHR106 can be utilized for therapeutic applications in GnRH hormone sensitive ovarian cancers and others as well as in the control of fertility regulations [27-29].

GHR106 was generated in mice immunized against synthetic peptides corresponding to N1-29 amino acid residues of the extracellular domains of human GnRH receptor and was found to behave like GnRH analogs, but with a much longer half-life than the decade peptide GnRH analogs known for their clinical indications in the field [30]. GnRH analogs have been used as drugs for fertility regulations to treat a variety of clinical conditions, such as ovulation disorders, endometriosis, uterine fibroids, precocious puberty and some types of cancers [27-29]. 


\begin{tabular}{|c|c|c|c|c|c|c|c|}
\hline Immunoglobulin chain & & Region & & Number of Similarities & & Percent Similarities & \\
\hline \multirow[b]{4}{*}{ Heavy Chain } & & FR1 & & $23 / 30$ & & $77 \%$ & \\
\hline & & FR2 & & $11 / 14$ & & $79 \%$ & \\
\hline & & FR3 & & $25 / 38$ & & $66 \%$ & \\
\hline & & & Subtotal & & $59 / 93$ & & $63 \%$ \\
\hline \multirow{11}{*}{ (n) } & & $\mathrm{JH}$ & & $10 / 11$ & & $91 \%$ & \\
\hline & & & Subtotal & & $10 / 11$ & & $91 \%$ \\
\hline & & CDR1 & & $5 / 5$ & & $100 \%$ & \\
\hline & & CDR2 & & $10 / 11$ & & $91 \%$ & \\
\hline & & CDR3 & & $4 / 4$ & & $100 \%$ & \\
\hline & & & Subtotal & & $19 / 20$ & & $95 \%$ \\
\hline & \multirow[t]{10}{*}{ Total } & & & $88 / 124$ & & $71 \%$ & \\
\hline & & FR1 & & $15 / 23$ & & $65 \%$ & \\
\hline & & FR2 & & $13 / 15$ & & $87 \%$ & \\
\hline & & FR3 & & $30 / 34$ & & $88 \%$ & \\
\hline & & FR4 & & $10 / 10$ & & $100 \%$ & \\
\hline \multirow[t]{6}{*}{ Light Chain } & & & Subtotal & & $68 / 82$ & & $83 \%$ \\
\hline & & CDR1 & & $17 / 17$ & & $100 \%$ & \\
\hline & & CDR2 & & $5 / 5$ & & $100 \%$ & \\
\hline & & CDR3 & & $9 / 9$ & & $100 \%$ & \\
\hline & & & Subtotal & & $31 / 31$ & & $100 \%$ \\
\hline & Total & & & $99 / 103$ & & $96 \%$ & \\
\hline Heavy and Light Chain & & Total & & $187 / 227$ & & $82 \%$ & \\
\hline
\end{tabular}

Table 2: Comparisons of amino acid sequences homology in the FR and CDR domains in the Fab region of hRP215and mRP215.

Biochemical and immunological experiments were employed to demonstrate that murine GHR106 has high specificity and affinity to GnRH receptor [17]. In vitro apoptotic and anti-proliferative assays, were performed to document that GHR106 at $\mu \mathrm{g} / \mathrm{ml}$ concentration range reacts with the surface of almost all cancer cells or cancerous tissues in humans, similar to the biological actions of those decade peptide GnRH analogs $[9,17]$.

Complement-dependent cytotoxicity (CDC) reactions can be induced in cancer cells in the presence of $\mu \mathrm{g} / \mathrm{ml}$ range of murine GHR106. Growth inhibition by murine GHR106 of tumor cells implanted in nude mice with OC-3-VGH ovarian cancer cells was also demonstrated in nude mouse models $[9,20,31]$. However, it is essential to modify the original murine GHR106 Mab into humanized forms, prior to therapeutic applications as anti-cancer or fertility regulation drugs in humans.

\section{Process of humanization of murine GHR106 Mab}

For humanizations of GHR106, human framework donor selection was made through search of germline. This was followed by rearrangement of the human IgG data base by using $\mathrm{V}_{\mathrm{L}}$ and $\mathrm{V}_{\mathrm{H}}$ sequence with or without CDRs [9]. For $\mathrm{V}_{\mathrm{L}}$ and $\mathrm{V}_{\mathrm{H}}$ sequences, the best hits in each group were aligned. Finally, one germline FR donor and one rearranged (mature) FR domains based on sequence similarity and other factors were selected. These factors included CDR length, canonical structure, proline residues at key positions or factors which may affect proper folding of humanized antibody. The homology modeling was used to obtain template antibody structure by search of the PDB data base for template antibody $\mathrm{V}_{\mathrm{L}}$ and $\mathrm{V}_{\mathrm{H}}$ sequences with or without CDR. The antigen binding region of the antibody structure model was optimized through the CDR loop data-base and canonical structure class as well as comparison with the template structure. Structural modeling's as well as back mutation were performed to those residues that are predicted significantly to affect CDR loop structure. Based on these considerations, combinations of back mutation were designed to balance the minimal requirements of such process. Low immunogenicity to humans and maximal preservation of antigenbinding affinity are obtained. After four rounds of humanization designs, several humanized GHR106 Mabs are generated, expressed and affinity-purified.

To perform antigen binding assays, cancer cell-coated microwell plates were used to test the affinity of antibodies. Supernatants containing the various recombinantly-produced antibodies from transfected $\mathrm{CHO}$ cells were serially diluted and added to cell-coated wells for $1 \mathrm{hr}$ incubation at $37^{\circ} \mathrm{C}$. The wells in plates were subsequently washed with wash buffer; and then incubated with HRP-conjugated goat anti-human IgG for color development (20 min to $1 \mathrm{~h}$ ). The color intensity was determined spectrophotometrically by a microplate reader. All humanized isoforms were produced with human IgG1 heavy chain constant regions and light chain Kappa constant regions. Humanization of GHR106 has been successfully completed after fourth rounds of humanization. All of these humanized light chains and heavy chains showed good potency, comparable to those of mGHR106. H40 and L42 were selected for later humanized antibody assays and appeared to be the best humanized pair with comparable potency as the parental mGHR106 with a dissociation constant $(\mathrm{Kd})$ of 7.0 $\mathrm{nM}$ to GnRH receptor on cancer cells (Table 1B). This antibody was designated as hGHR106 and mass produced by a typical in vitro culture with minibioreactors. Amino acid sequences of heavy chain and light chain of several humanized forms of GHR106 with those of murine GHR106 are shown in Figure 3 for comparisons. Also for comparisons are sequence homologies in the CDR and FR regions of murine and humanized isoforms presented in Table 3.

\section{Comparative Biochemical and Immunological Studies for Demonstration of Bioequivalence}

mRP215 and hRP215 were employed to assess the bioequivalence of their respective ability to induce apoptosis to cancer cells in culture. At either high $(10 \mu \mathrm{g} / \mathrm{ml})$ or low $(1 \mu \mathrm{g} / \mathrm{ml})$ concentrations of RP215, 
both were shown to induce apoptosis when analyzed by TUNEL assay [9]. In contrast, incubations with normal mouse IgG or human IgG of the same concentrations do not have any significant effects on the apoptosis of cancer cells (Figure 4A).

Similar experiments were also performed to compare between mGHR106 and hGHR106 for induced apoptosis of cancer cells. Results indicated that both were found to induce apoptosis of cancer cells even at the concentration of $1 \mu \mathrm{g} / \mathrm{ml}$. Results of these studies are presented in Figure 4B.

CDC assay was also employed to demonstrate the bioequivalence between murine and humanized antibodies in inducing complementdependent cytotoxicity. Both forms of RP215 Mabs were found to have significant CDC to cultured cancer cells. Similarly, both murine and humanized forms of GHR106 Mabs were also found to be biosimilar inducing CDC to cultured cancer cells even at concentration range of $1-10 \mu \mathrm{g} / \mathrm{ml}$. Results of such comparative analysis are summarized in Figure 5A. In contrast, GnRH antagonist, Antide, did not exhibit any activities for $\mathrm{CDC}$ as expected under the same molecular concentration range [31] and culture conditions. Both mGHR106 and hGHR106 are equally effective in inducing CDC to OC-3-VGH ovarian cancer cells as well as others (Figure 5B).

\section{Discussion}

Based on many previous biochemical and immunological studies, two murine Mabs (RP215 and GHR106) were selected as candidates for anti-cancer drug development targeting ovarian cancer [7,9,20,31].

The molecular mechanisms of action of these two Mabs have been more or less elucidated through in vitro studies [7,9,20,31]. RP215 reacts mainly with a carbohydrate-associated epitope on the heavy chains of immunoglobulins expressed by cancer cells (CA215). RP215 serves to block activities of cancer cell-expressed immunoglobulins which are essential for growth/proliferation of cancer cells $[5,6,32]$. On the other hand, GHR106 serves as GnRH analogs of decapeptides [27]. Both GHR106 Mab and GnRH analogs were found to affect growth inhibition or induce apoptosis of cancer cells upon the surface receptor bindings [9,27]. Furthermore, GHR106 also induces CDC activity due to specific antibody binding on cancer cell surface. In contrast, peptide analogs of $\mathrm{GnRH}$ do not have such a CDC activity which is unique to the surface-bond antibodies $[9,27]$.

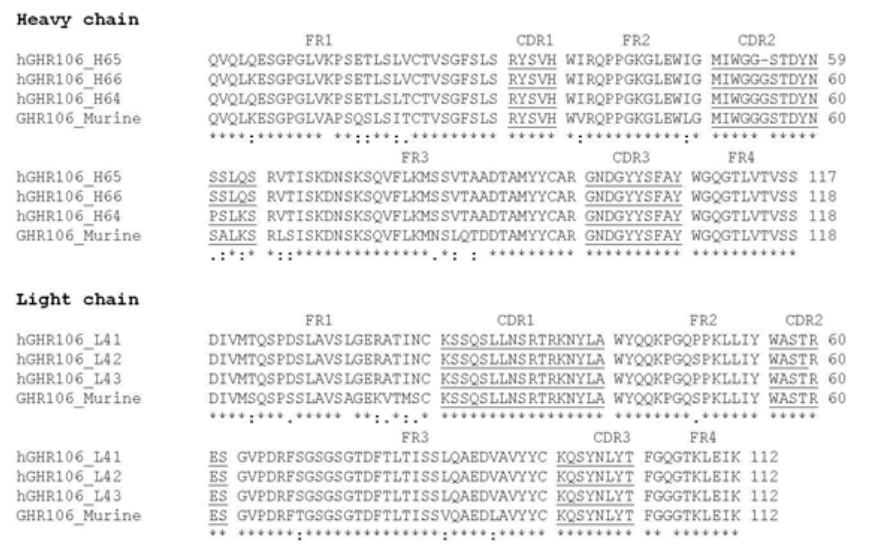

Figure 3: Comparisons of amino acid sequence of mGHR106 Mab and three different hGHR106 Mabs in the Fab regions of GHR106 Mabs. The FR/CDR domains are defined along with the deduced sequence for comparisons.
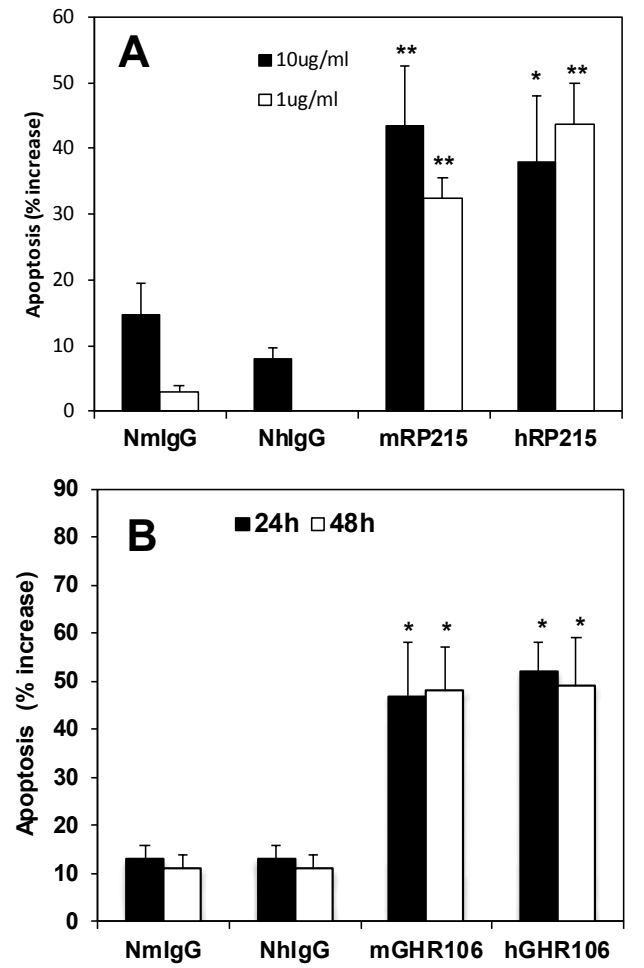

Figure 4: (A) Induced apoptosis on treated cultured OC-3-VGH cancer cells by normal mouse lgG (NmlgG) (Lane 1), normal human IgG (NhlgG) (Lane 2), mRP215 (Lane 3), and hRP215 (Lane 4) for 24 hour incubation. Open and solid column represent $1 \mu \mathrm{g} / \mathrm{ml}$ and $10 \mu \mathrm{g} / \mathrm{ml}$, respectively of the ligands used for the apoptosis assay. (B) Induced apoptosis on treated cultured OC3-VGH cancer cells by normal mouse IgG (NmlgG) (Lane 1), normal human lgG (NhlgG) (Lane 2), mGHR106 (Lane 3), and hGHR106 (Lane 4) (10 $\mu \mathrm{g} /$ $\mathrm{ml}$ ). Solid and open column represent the corresponding data obtained for 24 hour or 48 hour incubation, respectively. Statistical significance at $* p<0.01$ and ${ }^{* *}$ : $p<0.001$, see Reference $[23,27]$.

Generally speaking, there are several commonly known applications for these two humanized monoclonal antibodies, when utilized for immunotherapy of ovarian cancer. These humanized antibodies can be infused separately to patients and will target specifically the sites of ovarian cancer inside the human body to induce apoptosis as well as CDC reactions of ovarian cancer cells as demonstrated previously by cell-based in vitro assays as well as in vivo nude mouse experimental models [20].

Alternatively, these antibodies can be chemically modified with attachments of cytotoxic drugs of small molecules followed by infusion for further enhancement of cytotoxic activities in vivo. These antibodies can also be radio-labeled with $\mathrm{I}^{131}$ or others. As demonstrated previously with $\mathrm{I}^{131}$-labeled murine RP215 monoclonal antibody was shown to enhance the cytotoxicity of cancer cells by these modified antibodies [20].

In view of the fact that these two Mabs were shown to target cancer cells of different tissue origins, their therapeutic applications in human cancer will certainly not be limited to that of ovary. Other indications including that of lung, stomach or breast will be considered in the near future, when the therapeutic efficacy with ovarian cancer can be demonstrated.

As demonstrated in this study, humanized forms of RP215 
Citation: Lee G, Huang C, Ge B (2014) Two Distinct Humanized Monoclonal Antibodies for Immunotherapy of Ovarian Cancer. J Cancer Sci Ther 6: 110-116. doi:10.4172/1948-5956.1000258

and GHR106 Mabs have been successfully generated. Further characterizations of these humanized counterparts revealed that the humanized and murine isoforms are bioequivalent in terms of the affinity and specificity to their respective cognate antigens, CA215 and human GnRH receptor (Figure 4 and 5).

The affinity constants between various RP215 isoforms were determined by typical EIA binding assays (Figure 2 and Table 1). The ones with affinity closer to the original murine RP215 ( 4nM) or human/mouse chimeric RP215 were selected for scale up productions and subsequent characterizations. TUNEL Apoptosis assays and
CDC assays were employed to evaluate the biosimilarity between the murine and humanized forms of RP215 as shown in Figure 4A. Similar evaluations of murine and humanized GHR106 also led to the same conclusion of their biosimilarity (Figure 5A).

The dissociation constants (Kd's) of humanized RP215 and GHR106 Mabs were determined to be comparable to those of murine counter parts. Therefore, with an in vivo administration of $20 \mathrm{mg} / \mathrm{kg}$ body weight which is maximally tolerated, the average concentration of infused humanized antibody may be on the order of $250 \mu \mathrm{g} / \mathrm{ml}$ (assuming $50 \mathrm{~kg}$ body weight) in human circulation. This concentration
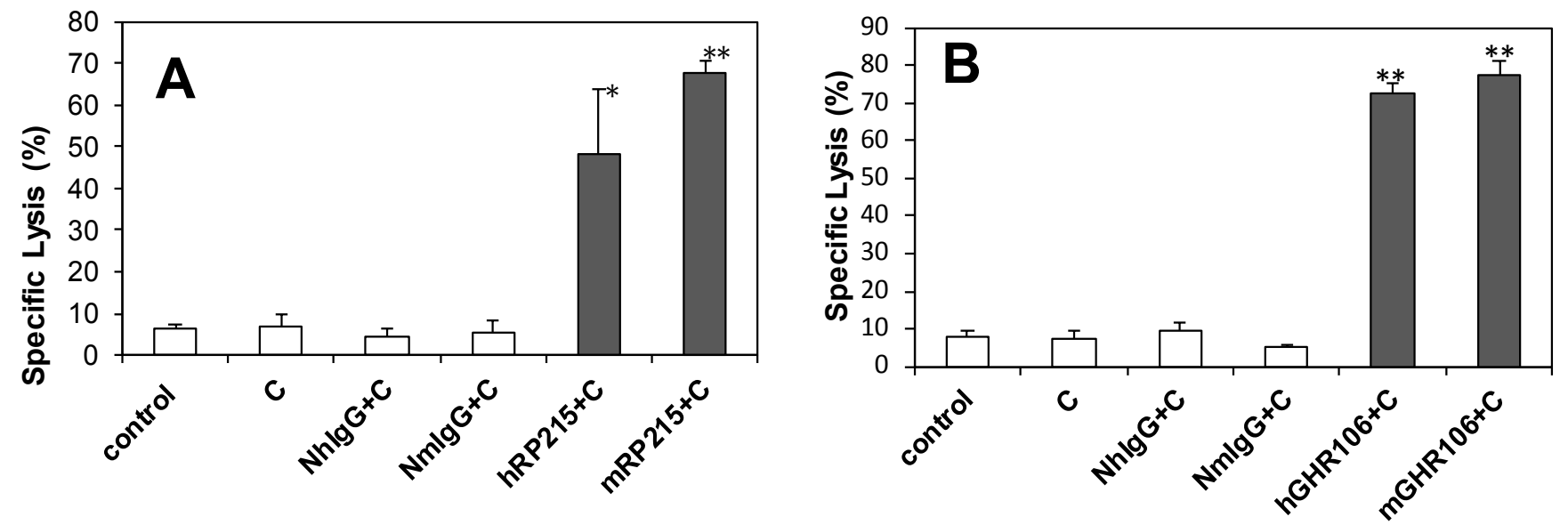

Figure 5: (A) Complement-dependent cytotoxicity (CDC) assay to demonstrate the effect of mRP215 Mab and its humanized form, hRP215 Mab, on the complementdependent cell lysis of OC-3-VGH ovarian cancer cells (2 hour incubation). Lane 1: no treatment (control); Lane 2: $3 \mu \mathrm{L}$ freshly prepared rabbit baby complement/mL (C); Lane 3: normal human lgG (10 $\mu \mathrm{g} / \mathrm{ml}$ plus complement) (NhlgG+C); Lane 4: normal mouse lgG (10 $\mu \mathrm{g} / \mathrm{ml}$ plus complement)(NmlgG+C); Lane 5: hRP215 (10 $\mu \mathrm{g} / \mathrm{ml}$ plus complement) (hRP215+C); Lane 6: $\mathrm{mRP} 215\left(10 \mu \mathrm{g} / \mathrm{ml}\right.$ plus complement) (mRP215+C). Statistical significance at * $\mathrm{P}<0.01$ and ${ }^{* *} \mathrm{P}<0.001 \mathrm{with}$ error bar indicated for duplicated experiments. (B) Similar experiments of mGHR106 Mab and its humanized form, hRP215 Mab on the complement-dependent cell lysis of OC-3-VGH ovarian cancer cell. See Reference $[23,27]$.

\begin{tabular}{|c|c|c|c|c|c|c|c|}
\hline Immunoglobulin chain & & Region & & Number of Similarities & & Percent Similarities & \\
\hline & & FR1 & & $24 / 30$ & & $80 \%$ & \\
\hline & & FR2 & & $12 / 14$ & & $86 \%$ & \\
\hline & & FR3 & & $27 / 37$ & & $73 \%$ & \\
\hline & & FR4 & & $11 / 11$ & & $100 \%$ & \\
\hline \multirow[t]{10}{*}{ Heavy Chain } & & & Subtotal & & $74 / 82$ & & $80 \%$ \\
\hline & & CDR1 & & $5 / 5$ & & $100 \%$ & \\
\hline & & CDR2 & & $11 / 11$ & & $100 \%$ & \\
\hline & & CDR3 & & $10 / 10$ & & $100 \%$ & \\
\hline & & & Subtotal & & $26 / 26$ & & $100 \%$ \\
\hline & Total & & & $100 / 108$ & & $93 \%$ & \\
\hline & & FR1 & & $16 / 23$ & & $70 \%$ & \\
\hline & & FR2 & & $14 / 15$ & & $93 \%$ & \\
\hline & & FR3 & & $31 / 34$ & & $92 \%$ & \\
\hline & & FR4 & & $9 / 10$ & & $90 \%$ & \\
\hline \multirow[t]{6}{*}{ Light Chain } & & & Subtotal & & $70 / 82$ & & $85 \%$ \\
\hline & & CDR1 & & $17 / 17$ & & $100 \%$ & \\
\hline & & CDR2 & & $5 / 5$ & & $100 \%$ & \\
\hline & & CDR3 & & $8 / 8$ & & $100 \%$ & \\
\hline & & & Subtotal & & $30 / 30$ & & $100 \%$ \\
\hline & Total & & & $100 / 112$ & & $89 \%$ & \\
\hline Heavy and Light Chain & & Total & & $200 / 220$ & & $91 \%$ & \\
\hline
\end{tabular}

Table 3: Comparisons of amino acid sequences homology in the FR and CDR domains in the Fab region of hGHR106and mGHR106. 
is approximately 300 fold higher than that of the Kd's. Based on this estimate, the maximum therapeutic efficacy can be easily achieved, given the fact that there humanized antibodies have an average half-life of 5-15 days.

Amino acid sequence homologies in the variable regions (CDRs and FRs) between humanized and murine isoforms of either RP215 or GHR106 were compared. As shown in Table 2 and 3, it was revealed that the majority of alternations were found in the FR regions (homology $65 \%$ to $100 \%$ ) and CDR regions, on the other hand, are kept relatively intact (homology $\geq 91 \%$ ). Nevertheless, the biosimilarity between murine and humanized isoforms could be demonstrated through the binding assay as well as related biological and immunological studies (Figure 4 and 5).

Consistent with our previous observations, a recent report by $\mathrm{Yu}$ et al. revealed that RP215 and its single chain Fab fragments were found to inhibit many cancer cells by inducing cell cycle arrest at G0/ G1 phase in breast cancer [33]. Therefore, the mechanism of RP215 to inhibit cell cycle regulations can be supported by this observation. We believe that RP215 which targets the "sugar" epitope mainly on cancer immunoglobulins and induces cell growth inhibition can be a good basis for future anti-cancer drug developments.

Based on the results of our current evaluation studies, biosimilar humanized RP215 and GHR106 Mabs have been successfully generated, produced and characterized. Preclinical evaluations should be warranted and may lead to successful developments of these two anticancer drugs for the immunotherapy of ovarian cancers $[4,9,20,34]$.

\section{Acknowledgement}

This research project was supported in parts by NRC-IRAP program (\#794354) of Canada. Helpful discussion on this topic with Dr. Chichi Liu and contract research work by Lakepharma Inc. (Belmont, CA) is acknowledged.

\section{References}

1. Lee CY, Chen KW, Sheu FS, Tsang A, Chao KC, et al. (1992) Studies of a tumor-associated antigen, COX-1, recognized by a monoclonal antibody. Cancer Immunol Immunother 35: 19-26.

2. Lee G, Laflamme E, Chien $\mathrm{CH}$, Ting $\mathrm{HH}$ (2008) Molecular identity of a pan cancer marker, CA215. Cancer Biol Ther 7: 2007-2014.

3. Lee G, Ge B (2009) Cancer cell expressions of immunoglobulin heavy chains with unique carbohydrate-associated biomarker. Cancer Biomark 5: 177-188.

4. Lee G, Zhu M, Ge B, Potzold S (2012) Widespread expressions of immunoglobulin superfamily proteins in cancer cells. Cancer Immunol Immunother 61: 89-99.

5. Qiu X, Zhu X, Zhang L, Mao Y, Zhang J, et al. (2003) Human epithelial cancers secrete immunoglobulin $\mathrm{g}$ with unidentified specificity to promote growth and survival of tumor cells. Cancer Res 63: 6488-6495.

6. Li M, Zheng H, Duan Z, Liu H, Hu D, et al. (2012) Promotion of cell proliferation and inhibition of ADCC by cancerous immunoglobulin expressed in cancer cell lines. Cell Mol Immunol 9: 54-61.

7. Lee $\mathrm{G}, \mathrm{Ge} \mathrm{B}$ (2010) Inhibition of in vitro tumor cell growth by RP215 monoclonal antibody and antibodies raised against its anti-idiotype antibodies. Cancer Immunol Immunother 59: 1347-1356.

8. Lee CY, Ho J, Chow SN, Yasojima K, Schwab C, et al. (2000) Immunoidentification of gonadotropin releasing hormone receptor in human sperm, pituitary and cancer cells. Am J Reprod Immunol 44: 170-177.

9. Lee G, Cheung AP, Ge B, Zhu M, Giolma B, et al. (2012) CA215 and GnRH receptor as targets for cancer therapy. Cancer Immunol Immunother 61: 18051817.

10. Kaiser UB, Zhao D, Cardona GR, Chin WW (1992) Isolation and characterization of cDNAs encoding the rat pituitary gonadotropin-releasing hormone receptor. Biochem Biophys Res Commun 189: 1645-1652.
11. Kakar SS, Jennes L (1995) Expression of gonadotropin-releasing hormone and gonadotropin-releasing hormone receptor mRNAs in various non-reproductive human tissues. Cancer Lett 98: 57-62.

12. Kakar S1, Musgrove LC, Devor DC, Sellers JC, Neill JD (1992) Cloning, sequencing, and expression of human gonadotropin releasing hormone $(\mathrm{GnRH})$ receptor. Biochem Biophys Res Commun 189: 289-295.

13. Karande AA, Rajeshwari K, Schol DJ, Hilgers JH (1995) Establishment of immunological probes to study human gonadotropin-releasing hormone receptors. Mol Cell Endocrinol 114: 51-56.

14. Reinhart J, Mertz LM, Catt KJ (1992) Molecular cloning and expression of cDNA encoding the murine gonadotropin-releasing hormone receptor. J Biol Chem 267: 21281-21284

15. Tsutsumi M, Zhou W, Millar RP, Mellon PL, Roberts JL, et al. (1992) Cloning and functional expression of a mouse gonadotropin-releasing hormone receptor. Mol Endocrinol 6: 1163-1169.

16. Chien $\mathrm{CH}$, Chen $\mathrm{CH}$, Lee $\mathrm{CY}$, Chang TC, Chen RJ, et al. (2004) Detection of gonadotropin-releasing hormone receptor and its mRNA in primary human epithelial ovarian cancers. Int J Gynecol Cancer 14: 451-458.

17. Lee G, Ge B (2010) Growth inhibition of tumor cells in vitro by using monoclonal antibodies against gonadotropin-releasing hormone receptor. Cancer Immuno Immunother 59: 1011-1019.

18. Mørch LS, Løkkegaard E, Andreasen AH, Krüger-Kjaer S, Lidegaard O (2009) Hormone therapy and ovarian cancer. JAMA 302: 298-305

19. Waldmann TA (2003) Immunotherapy: past, present and future. Nat Med 9 269-277.

20. Lee G, Chu RA, Ting HH (2009) Preclinical assessment of anti-cancer drugs by using RP215 monoclonal antibody. Cancer Biol Ther 8: 161-166.

21. Wu TT, Kabat EA (1970) An analysis of the sequences of the variable regions of Bence Jones proteins and myeloma light chains and their implications for antibody complementarity. J Exp Med 132: 211-250.

22. Chothia C, Lesk AM, Tramontano A, Levitt M, Smith-Gill SJ, et al. (1989) Conformations of immunoglobulin hypervariable regions. Nature 342: 877-883.

23. Tang $Y$, Zhang $H$, Lee $G$ (2013) Similar gene regulation patterns for growth inhibition of cancer cells by RP215 or anti-antigen receptors. J Cancer Sci Ther 5: 200-208.

24. Lee G, Ge B (2009) Cancer cell expressions of immunoglobulin heavy chains with unique carbohydrate-associated biomarker. Cancer Biomark 5: 177-188.

25. Lee G, Azadi P (2012) Peptide mapping and glycoanalysis of cancer cellexpressed glycoproteins CA215 recognized by RP215 monoclonal antibody. $J$ Carbohydr Chem 31: 10-30.

26. Lee G, Zhu M, Ge B, Cheung AP, Chien CH, et al. (2012) Carbohydrateassociated immunodominant epitope(s) of CA215. Immunol Invest 41: 317-336.

27. Lee G, Zhang H, Tang Y (2013) Anti-GnRH Receptor Monoclonal Antibodies as Bioequivalent Analogs of $\mathrm{GnRH}$. In: Gonadotropin-Releasing Hormone $(\mathrm{GnRH})$ : Production, Structure and Function, Imprint: Nova Biomedical: 157174

28. Yang-Feng TL, Seeburg PH, Francke U (1986) Human luteinizing hormonereleasing hormone gene $(\mathrm{LHRH})$ is located on short arm of chromosome 8 (region 8p11.2----p21). Somat Cell Mol Genet 12: 95-100.

29. Rao AJ, Moudgal NR (1984) Effect of LHRH injection on serum chorionic gonadotropin levels in pregnant bonnet monkey (Macaca radiata). IRCS Med Sci 12: 1105-1106.

30. Flanagan CA, Millar RP, Illing N (1997) Advances in understanding gonadotrophin-releasing hormone receptor structure and ligand interactions. Rev Reprod 2: 113-120.

31. Lee G, Zhu MG, Ge BX (2012) Potential monoclonal antibody therapy for the treatment of ovarian cancer. In: Farghaly SA (ed) Ovarian cancer - basic science perspective. InTech, Vancouver pp: 385-406.

32. Zheng H, Li M, Liu H, Ren W, Hu DS, et al. (2007) Immunoglobulin alpha heavy chain derived from human epithelial cancer cells promotes the access of $S$ phase and growth of cancer cells. Cell Biol Int 31: 82-87. 
Citation: Lee G, Huang C, Ge B (2014) Two Distinct Humanized Monoclonal Antibodies for Immunotherapy of Ovarian Cancer. J Cancer Sci Ther 6: 110-116. doi:10.4172/1948-5956.1000258

33. Yu F, Wang Y, Xiao Y, He Y, Luo C, Duan D, et al. (2014) RP215 single chain fragment variable and single domain recombinant antibodies induce cell cycle arrest at G0/G1 phase in breast cancer. Mol Immunol 59: 100-109.
34. Lee G (2012) Cancerous immunoglobulins and CA215: implications in cancer immunology. Am J Immunol 8: 101-116.

This article was originally published in a special issue, Novel Targeted

Therapies for Patients with Ovarian Cancer handled by Editor. Dr.

Samir A Farghaly, Cornell University, USA 